\title{
RESULTS FROM THE IMPLEMENTATION OF AID EFFECTIVENESS PRINCIPLES IN THE HEALTH SECTOR IN MALI
}

\begin{abstract}
Currently there is a climate of high expectations within the international community with regard to producing demonstrable results of aid effectiveness in the health sector both at global and developing country level. Yet, measuring the results from aid effectiveness presents methodological challenges. Existing evaluation frameworks are not sufficiently geared toward whether and how practices have changed. This paper presents a framework for measuring results from implementing the aid effectiveness principles at three levels: implementation process, system strengthening, and outcomes/impact. We developed it in the context of the monitoring of the results from the aid effectiveness agenda in the health sector in Mali. Despite some changes in behavior resulting in increased aid effectiveness and improved results at system and impact level, these principles have not been fully implemented so far. Expectations in terms of health outcomes should thus be realistic.
\end{abstract}

Keywords: aid effectiveness, evaluation framework, results, health sector, Mali 


\section{$\underline{\text { Introduction }}$}

The effectiveness of development assistance to poor countries has been a major area of concern for both academics and practitioners over the past two decades, and it is likely to remain so as budgets from traditional donors are currently under severe fiscal strain. Evaluations performed during the 1990's pointed out that the relative ineffectiveness of development aid was partly due to factors inherent in traditional aid modalities (namely standalone projects and structural adjustment programs), such as lack of coordination between donors, lack of coherence between donor-funded intervention and government operations, lack of capacity building and perverse effects over recipient administrations, and high transaction costs in managing aid funds. ${ }^{1}$ Hence innovative aid modalities, such as sectorwide approaches (SWAp), have been introduced and implemented in order to respond to these weaknesses. In March 2005, the donor community led by the OECD's Development Assistance Committee and partner countries signed the Paris Declaration on Aid Effectiveness and committed to respecting a number of principles presumed to increase aid effectiveness, such as ownership, alignment, harmonization, results-orientation and mutual accountability. These commitments were reaffirmed in 2008 through the Accra Agenda for Action and in 2011 through the Busan Partnership for Effective Development Co-operation.

Concerns for aid effectiveness are particularly high in the health sector where aid inefficiencies are related to a number of cumulative reasons both at global and country level. First, the global aid architecture in health is increasingly complex. ${ }^{2-5}$ Moreover, despite the dramatic increase in official development assistance for health over the past decade ${ }^{5,6}$, those flows are disproportionally targeted to fighting HIV/AIDS, malaria and other diseases, while strengthening health systems and service delivery is clearly insufficiently funded. ${ }^{4}$ Together with a number of political incentives, this creates a disconnection between aid flows and the 
actual country needs in term of disease burdens. ${ }^{3,7-9}$ At country level, aid for health is very fragmented and aid effectiveness continues to be undermined by donor agencies' administrative habits and institutional incentives favoring inefficient practices. While recognizing that global constraints percolate down to country level, this paper focuses on operational constraints encountered at country level.

At country level, first attempts to improve donor coordination and aid effectiveness in the health sector were launched in the late 1990s in the form of program-based approaches (PBAs), better known at sectorial level as SWAps. ${ }^{10}$ Since then, the concept of SWAp has evolved and many definitions have been proposed. ${ }^{11}$ We define it as a way of working between a government and donors, who work together to gradually establish a comprehensive and coherent sector-wide policy and strategy - that is, a common approach for the entire sector. $^{12}$ SWAps are definitely not a rigid model, but a dynamic process. ${ }^{13,14}$ Existing evaluations conclude that results from health SWAps are mixed: they are generally good at process level, but they are more difficult to be demonstrated in terms of health impacts. ${ }^{14,15}$ For instance, a systematic review of the impact of PBA in the health sector in six countries undertaken by the World Bank's Independent Evaluation Group in 2009 showed that SWAps were largely successful in terms of coordination, oversight, harmonization and alignment of development assistance, but only modestly in terms of improved sector stewardship and achievement of national health objectives. ${ }^{16}$ The success of a SWAp appears to depend on a number of institutional factors, notably stakeholders' commitments to tackle systemic issues and lead appropriate reforms so as to lift sector (and sometimes broader) constraints. ${ }^{13,14}$

SWAp principles have recently been reinvigorated by the launch in 2007 of the International Health Partnership and related initiatives (IHP+), which has become a major instrument at 
global and country level for implementing the aid effectiveness principles in the health sector. However, although major improvements in the way aid is delivered have been observed in recent years, significant progress is still needed to make health aid more effective., ${ }^{9,17}$

There is currently a climate of high expectations with regard to producing demonstrable results of aid effectiveness in the health sector, both at global and at developing country level. Over the past few years, efforts have been made to better track health aid expenditure, and some attempts are made today to quantify health aid effectiveness. ${ }^{5,6,9,18}$ The Paris Declaration and IHP + set forth a few objectives monitored by a limited number of process indicators reflecting better aid practices and better national systems, which in turn should produce better development results. In 2010, in consultations led by the World Health Organization (WHO), an operational framework was developed for the monitoring and evaluation of health system strengthening (HSS). It proposes the development of a single country platform for national monitoring and evaluation activities that can measure health system capacity as well as health system performance. ${ }^{19}$ That framework has now been adopted by IHP+ for measuring progress in HSS.

Yet, we argue in this paper that the existing frameworks aimed at evaluating the results of aid effectiveness do not pay sufficient attention to the changes in behavior on the field, nor to ultimate development results. We thus propose to assess the results from the implementation of aid effectiveness principles at three levels: implementation process, HSS, and outcomes/impact. 


\section{$\underline{\text { Methods }}$}

The three-level assessment framework below was developed in the context of the follow-up and stocktaking of the implementation of aid effectiveness principles in Mali performed by the authors since 2005. When starting to document the Malian SWAp experience, we were struck by the fact that while a lot of progress was made in formal terms (especially the inscription of all donor interventions within the national health plan, the participation of all significant stakeholders in the joint steering bodies, and improvements in joint programming tools), a number of behaviors were not changing. This is especially the case for donors maintaining projects targeted on specific health issues and/or geographic areas and sometimes managed through specific procedures, and donors continuing to organize bilateral missions and evaluations in addition to the joint ones.

That is why we decided to study more in-depth the implementation process of the initiatives in favor of aid effectiveness - starting from the SWAp to the Paris Declaration, budget support and IHP+. The successive case studies we performed rested on various methods from the analysis of existing documents and statistics to interviews with a wide variety of stakeholders belonging to the ministry of health $(\mathrm{MoH})$ and other ministries, donors, and civil society. They also rest on participative observation as one author has been working for the MoH for two decades, one has worked for a donor agency in Mali from 1997 to 2008, and one has been technical assistant there from 2007 to 2009 .

\section{Assessing the results from aid effectiveness}

The agenda for aid effectiveness is presumed to improve results at different levels (macro-, meso- and micro- level) through a causal relationship: (i) improved aid delivery practices at the international level (as monitored against the Paris principles for instance); this, in turn, is 
expected to lead to (ii) improved health systems and policies at the national level; which is also supposed to (iii) improve health service delivery at the operational level; and ultimately, (iv) impact health outcomes (e.g. immunization rates, use of health services, etc.) and health status (e.g. morbidity and mortality rates). The rationale underlying the Paris Declaration and IHP+ is often viewed simplistically as shown in Figure 1.

Figure 1 comes here

The monitoring mechanism of the Paris Declaration and IHP+ implementation is limited to process measures at the macro level, but there is growing pressure to demonstrate that there are also results at the other end of the process - that is, in terms of health status. Yet, producing development outcomes and impact takes time and necessitates intermediary processes and effective behavior change that also takes time and cannot be expected to produce results in health status overnight. Actually, the seemingly simple causal arrows in the figure above mask not only a number of changes in behavior and practice of considerable importance, but also other contextual influences (political, social, economic) that impact on results. The rationale underlying the Paris Declaration should thus take account of the complexity involved in reforms to increase aid effectiveness and rather be viewed as in Figure 2.

Figure 2 comes here

There are two important points to make here. Firstly, demonstrating that results are attributable to particular strategies from the agenda for aid effectiveness is tricky because from a methodological point of view, it is almost impossible to isolate the impact of such 
strategies from other confounding factors, including those outside the health sector - e.g. the considerable socio-economic influence on health status. ${ }^{20,21}$ Indeed, aid delivery systems, public programs and health systems are all complex, often interlinking systems that cannot be studied experimentally. ${ }^{22-24}$ Nevertheless comprehensive and contextualized research approaches can be used to gain useful insight into the impact of such strategies. ${ }^{25-27}$

Secondly, effectively implementing the principles of aid effectiveness (beyond the few indicators of the Paris Declaration) necessarily encompasses many changes in behavior and practice on the part of both donors and recipient countries. If the principles are not fully implemented and the behaviors have not changed consequently (as was for instance the case in Zambia where little improvement in predictability of resources and donor alignment to country financial management systems were observed), ${ }^{28}$ one cannot expect the (only partial) reform to produce results or impact on the subsequent levels of the system. Yet, when a reform (such as the Paris Declaration) is introduced, one rarely evaluates whether it has been implemented as it was conceived, nor whether it has produced the necessary behavior changes.

We argue in this paper that results from the agenda for aid effectiveness in the health sector can be measured at three levels. A first, critical step for evaluating the results from the Paris Declaration and other reforms such as IHP+ is to evaluate their implementation process as well as the direct effect it has had on changes in behavior for all stakeholders (donors, government, service providers, etc.). Such an evaluation allows not only verifying whether the agenda has been fully implemented, which is a result in itself, but also monitoring progress and increasing understanding of how and why outcomes can be improved. To understand how behaviors have changed (or not), a mixed method study design with a strong qualitative 
component (e.g. multiple case studies) should be used. Such methods also apprehend countryspecific features and enable understanding how processes and results interact within the local context.

A second level of evaluation is to assess how far donor support and implementation of Paris principles have contributed to the strengthening of the health system up to the level of service delivery. Indeed, there is mounting evidence showing that HSS is necessary to improve health outcomes, including the performance of vertical programmes. ${ }^{29,30}$ Such evaluations can be carried out with respect to the pillars of the health system, ${ }^{2}$ whilst bearing in mind that by definition these pillars interact with one another and therefore must all be tackled to improve results. ${ }^{23,31,32}$ For this second level, we recommend using an evaluation framework such as the one adopted by IHP+ mentioned above, that pays particular attention to the effects of donor interventions on HSS.

Finally, the third level where improvement is expected and should be measured is at health outcome/status level. As already mentioned, it is impossible to prove that observed changes in health outcomes and status are directly attributable to aid management reforms. Nevertheless, qualitative methods can help to understand which processes, and how far positive changes in health outcomes and status, can be attributed to improvements in aid delivery systems and HSS. ${ }^{\text {i }}$ This part of the results chain is also correctly handled by the operational framework adopted by IHP+ which provides guidance as for bith the type of information and the monitoring and evaluation actions that should be taken. Victora and colleagues also propose a national platform approach to evaluation design to large-scale programs that may be very useful, notably to increase the ownership of evaluation by domestic constituencies and deepen the understanding of contributing factors. ${ }^{24}$ 
The rest of this paper makes a synthesis of all the work the authors performed in Mali until the end of 2011 in view of taking stock of the experience of putting aid effectiveness principles into practice in the health sector. ${ }^{33-37}$ Note however that recent political troubles in Mali have led many donors to suspend their aid in March 2012, which unfortunately jeopardizes the progress reached during the past decade.

\section{Application of the evaluation framework to the health sector in Mali}

Mali is very dependent on official development assistance that accounted for close to $10 \%$ of gross domestic product and $30 \%$ of public expenditure in $2010 .^{38}$ The Government of Mali has been preoccupied by aid effectiveness since the 1990's, especially in the health sector. Indeed, the latter is very fragmented, with some fifty donors supporting the national health program (called PRODESS) operational plan, very often through specific management and reporting procedures. A health SWAp was launched in 1999, supported by a pooled fund mechanism. It has then been consolidated over time and today, the SWAp is based on the following components: (i) PRODESS, its strategic companion documents and their mediumterm expenditure framework define coherent sectorial strategies and constitute the unique programming framework of the sector; (ii) PRODESS steering bodies constitute the sole sectorial coordination framework, directed by the Government and drawing heavily on the participation of civil society; (iii) PRODESS implementation and results monitoring is carried out jointly by steering bodies. The process was strengthened following the introduction of sector budget support in 2006, and the signing in April 2009 of the IHP+ national Compact that formalizes the commitment of the government of Mali and thirteen donors to jointly support the PRODESS in a common framework. ${ }^{37}$ 


\section{Level 1 assessment: implementation process}

When applying the "level 1" assessment of the framework proposed above to Mali, we found that some progress and positive changes have been observed in recent years that can be attributed to the agenda for aid effectiveness - starting from the SWAp to the Paris Declaration and IHP+ Compact - both on the donor and government side. On the donors' side, nearly all significant donors (including international NGOs and even some non-OECD donors, but excluding global funds) are actively represented at the coordination mechanisms of the SWAp. Many bilateral donors are using the PRODESS procedures and accounts to manage their funds, including at operational level. Several donors (the Netherlands, Canada, Spain and previously Sweden) provide or have provided sector budget support in the health sector, accounting for roughly $10-12 \%$ of the PRODESS financing since 2006 . Several "big" donors (including the European Commission and World Bank) provide global budget support with health conditionalities. With the signature of the IHP+ Compact, donors are encouraged to increase predictability of funding and announce in advance how and when funds will be disbursed; now several of them announce their funding for two or three years ahead. Some donors intervene in the sector through silent partnerships. Every year donors are invited to participate to the joint mission organized by the $\mathrm{MoH}$ in order to monitor changes in central structures and at field level. More effort is made, and in a more coherent way, to support health system strengthening, especially with respect to programming and statistics.

On the government side, the $\mathrm{MoH}$ has strengthened its collaboration with the Ministry of Finance, and an annual joint audit is organized. The MoH has complemented the PRODESS with policy documents aimed at providing a single, coherent framework for health system strengthening, notably with respect to human resources development, which had been identified as critical for improving results. The quality of information and analyses shared at PRODESS steering bodies has improved in recent years. Since the elaboration of the IHP+ 
Compact, the policy processes are more inclusive than ever. More resources are managed at the decentralized level, which is particularly necessary to get results in such a huge country as Mali. The $\mathrm{MoH}$ is also progressively strengthening its collaboration with the private sector. $^{36,37}$

These changes in practice and behavior have undoubtedly enabled to reach some progress in terms of aid effectiveness. This is especially the case with regards to $\mathrm{MoH}$ leadership, ownership and capacities; coordination, coherence and alignment of donor interventions with the national plan; efforts to align on domestic processes and systems or at least to harmonize donor interventions (e.g. joint arrangements for budget support); and trust building between partners enabling to solve difficulties when they arise. A virtuous circle has thus developed between the Paris Declaration components: for instance, alignment on the national program has underlined the need to strengthen $\mathrm{MoH}$ capacities, and concurrent support has reinforced its leadership and its capacity to direct the program.

However, despite this progress, all donors have not fulfilled their commitments and some unfavorable practices continue, so that the principles of the Paris Declaration and IHP + have yet to been fully implemented. A variety of examples can be provided. Donors continue to proliferate: about fifty donors are active in the health sector, of which only thirteen have signed the IHP+ Compact. A large number of projects targeting specific health problems and/or geographical areas are still managed in the sector. Some important donors including the Global Fund (despite being a member of IHP+ at global level) and USAID, continue to use separate management units and/or procedures. Many donors do not uphold their commitments to announce disbursements sufficiently in advance nor to make their disbursements on time, even when conditionalities are fulfilled. Nearly all donors active in the 
sector continue to organize bilateral missions from headquarters as well as various workshops, very often imposing their own agenda to the government. Technical assistance is still planned and managed bilaterally. While yearly audits of the PRODESS are organized at national level, up to five donor specific audits have been conducted in 2010, putting a lot of pressure on the MoH's financial department - which has been identified as a major factor impeding the

implementation of planned activities. ${ }^{36,37}$ As a result, transaction costs (even if difficult to measure $)^{39}$ were not perceived by interviewed stakeholders as decreasing. ${ }^{33}$

\section{Level 2 assessment: HSS}

Even if HSS is a process that also requires behavioral changes at the operational level, and therefore takes time, we can say that improvements in aid effectiveness have produced positive results at the system level that are likely to improve health outcomes. The Malian health system has a pyramidal structure, based on the health-care district system. A consensual (Delphi) analysis of the Malian health system performed in 2007 shows that it can count on a great deal of strengths, but faces a number of weaknesses as well, especially in terms of human resource management, so that health care quality is quite low. ${ }^{35}$

Turning to level 2 of the framework proposed above, one observes that the $\mathrm{MoH}$ capacities have been strengthened, notably those of the Planning Unit which has been reinforced by additional staff, trainings and material. Consequently, governance of the health sector has improved a lot since the launch of the SWAp, especially with regards to coordination, coherence and complementarity of interventions. Decentralization, service packages, as well as the quality of the programming, planning and budgeting processes have also improved a lot, leading to a more efficient use of resources. Some progress has been initiated in human resource management, with the issue in 2009 of a national plan for human resources for health 
development. As for the other pillars of the health system, ${ }^{2}$ coverage in terms of infrastructures significantly improved, particularly in initially disadvantaged regions; the availability of and access to essential medicines has improved; and the national health information system has been strengthened, notably thanks to support provided to the staff in charge of collecting statistics. ${ }^{36,37}$

\section{Level 3 assessment: outcomes/impact}

Finally, turning to level 3 of the evaluation framework, recent evaluations show that improved donor coordination and efforts to support HSS have progressively improved the population's access to health services, their utilization and ultimately, health outcomes and status (including a reduction in regional disparities). ${ }^{39}$ Indeed, the health sector in Mali has been performing well over the past decade as most indicators of outputs and outcomes have progressed. ${ }^{40}$ According to WHO and UNICEF estimates, the maternal mortality ratio has evolved from $930 / 100,000$ in 1990 , to 770 in 2000,620 in 2005 and 540 in $2010 ;{ }^{41}$ and the under-5 mortality ratio has decreased from 255 per 1,000 in 1990 to 213 in 2000,195 in 2005 and 178 in $2010 .{ }^{42}$ A more recent survey also shows that the assisted delivery rate has grown from $40.6 \%$ in 2001 to $49.0 \%$ in 2006 and $56.6 \%$ in 2010 ; thanks to routine vaccination, immunization rates have progressed a lot (passing from $48.7 \%$ in 2001 to $68.4 \%$ in 2006 and $73 \%$ in 2010 for measles; and from $39.6 \%$ in 2001 to $61.9 \%$ in 2006 and $72.1 \%$ in 2010 for DTC3); and the rate of underweight children under-five years of age have also decreased (from $33.2 \%$ in 2001 to $26.7 \%$ in 2006 and $18.9 \%$ in 2010). ${ }^{40,43}$

As pointed, it is impossible to prove a linear, causal link between implementation of the Paris principles (level 1), improvements in health systems (level 2) and health outcomes (level 3). Nevertheless, qualitative methods enable to identify the most plausible factors at the origin of results. In Mali, beyond clear correlations between most outcome indicators and the increase 
in the number of health facilities and health staff in regions, key informants interviewed stressed the following factors as explaining improvement in health outcomes and status These include the scaling-up - by the MoH with the support of partners - of high-impact strategies (immunization, distribution of insecticide-treated mosquito nets and artemisinin-based combination therapies) and those aiming to improve access to health services for the poor (some free health services, organization of referral and evacuation at the health district level, ...), for women (reproductive health standards and procedures, free caesareans, emergency obstetric care, ...) and for children (expanded program on immunization, integrated management of childhood illness, prevention of mother-to-child transmission of HIV $)^{\mathrm{ii}}$. Other factors identified as critical for health improvements were better availability of and access to medicines and health products, e introduction of new medicines in the framework of the National Malaria Control Program, and increased resources allocated to the regions with greater attention to reducing regional inequalities. Finally, better harmonization of donors yielding more effective resource management (e.g. integrated campaigns), and the development of the private healthcare sector, have also been identified as contributing to improvements. ${ }^{38}$ Many of these determining factors have been influenced by the principles of aid effectiveness, notably through the comprehensive sector dialogue led in the context of the SWAp.

\section{$\underline{\text { Conclusion }}$}

We argue in this paper that although existing evaluation frameworks developed in the context of the Paris Declaration (early-process indicators) and IHP+ (HSS) are undoubtedly useful, they are not sufficient to evaluate the results achieved from the implementation of aid effectiveness principles at country level. Indeed, they do not pay enough attention to understanding whether and how behaviors have changed at donor, central and operational 
levels, and thus how reforms have actually been implemented. Yet, in reality, our case study of the health sector in Mali clearly shows that the commitments to aid effectiveness have only been partially implemented so far - thus there is a "two-speed implementation" of the aid effectiveness principles. And we have no reason to believe that it is very different in other sectors or countries facing a similar profile of aid dependence.

The agenda for aid effectiveness in the health sector has generated high expectations (especially in the very fragmented health sector), perhaps underestimating the extent and complexity of the reforms required, and therefore the time needed, for its implementation. Thus in addition to political and other constraints at global level that cause health aid inefficiencies, even at country level, the aid effectiveness principles guide a long-term reform process. It is therefore unrealistic to expect a radical change to happen overnight On the contrary, monitoring more in-depth the "first level" of our evaluation framework is essential in order to discern the extent of the implementation of the agenda for aid effectiveness including what the constraining factors are and why, what reforms have led to improvements and why, and the impact on population health. However, as the recent high level forum in Busan emphasized, today nobody can be satisfied with progress made in aid effectiveness alone: development results must also be demonstrated. Even if it is extremely difficult to prove causal links between the three levels of our evaluation framework, our case study in Mali shows that using qualitative methods can be useful to identify the most plausible factors at the origin of results. 


\section{REFERENCES}

${ }^{1}$ World Bank (1998) Assessing Aid: what works, what doesn't, and why? Policy Research Report. New York: Oxford University Press.

${ }^{2}$ World Health Organization (2007) Everybody's business: strengthening health systems to improve health outcomes: WHO's framework for action. Geneva: WHO.

${ }^{3}$ Dodd, Rebecca and Peter S. Hill (2007) The Aid Effectiveness Agenda: Bringing Discipline to Diversity in Global Health? Global Health Governance I(2).

${ }^{4}$ Piva, P., and Dodd, R. (2009) Where did all the aid go? An in-depth analysis of increased health aid flows over the past 10 years. Bulletin of the World Health Organization 87: 930-39.

${ }^{5}$ IHME (2012) Financing Global Health 2011: Continued Growth as MDG Deadline Approaches. Institute for Health Metrics and Evaluation: University of Washington.

${ }^{6}$ Ravishankar, N., Gubbins, P., Cooley, R.J., Leach-Kemon, K., Michaud, C.M., Jamison, D.T., and Murray, C. (2009) Financing of global health: tracking development assistance for health from 1990 to 2007. Lancet 373(9681): 2113-2124.

7 Esser, D. (2009) More Money, Less Cure: Why Global Health Assistance Needs Restructuring. Ethics \& International Affairs, Volume 23, Issue 3 225-234.

${ }^{8}$ Esser, D. and K. Keating Bench (2011) Does Global Health Funding Respond to Recipients' Needs? Comparing Public and Private Donors' Allocations in 2005-2007. World Development vol.39 no.8 pp 1271-1280.

${ }^{9}$ Duran, D. and A. Glassman (2012) An Index of the Quality of Official Development Assistance in Health, CGD Working Paper 287. Washington: Center for Global Development.

${ }^{10}$ Cassels, A. (1997) A guide to sector-wide approaches for health development: concepts, issues and working arrangements. Geneva: World Health Organization.

${ }^{11}$ Walford, V. (2007) A review of health sector wide approaches in Africa. HLSP Technical Paper. 
12 Zinnen, V., S. Laokri, and E. Paul (2009) Vers un nouveau paradigme de l'aide au développement : 1'approche sectorielle en santé, quels constats ? in H. Sanni Yaya (Ed.), Le défi de l'équité et de l'accessibilité en santé dans le tiers-monde, L'Harmattan, pp. 329-349.

${ }^{13}$ Paul, C., E. Paul, and V. Zinnen (2008) Health SWAps: for a sustainable development of healthcare systems in low-income countries. Chapter 10 in Cholewka, P., and M. Motlagh (Eds.), Health Capital and Sustainable Socioeconomic Development, Taylor \& Francis, pp. 191-215.

${ }^{14}$ Paul, E., S. Laokri, A. Robert, V. Zinnen, and B. Dujardin (2009) SWAPs in motion: Lessons from case studies in six African countries. Tropical Medicine \& International Health 14 Supplement 2, p. 18.

${ }^{15}$ Chansa, C., J. Sundewall, D. McIntyre, G. Tomson, and B. Forsberg (2008) Exploring SWAp's contribution to the efficient allocation and use of resources in the health sector in Zambia. Health Policy and Planning, Vol. 23, 2008, pp. 244-251.

${ }^{16}$ Vaillancourt, D. (2009) Do Health Sector-Wide Approaches Achieve Results? Emerging Evidence and Lessons from Six Countries - Bangladesh, Ghana, Kyrgyz Republic, Malawi, Nepal, Tanzania. IEG Working Paper 2009/4, Washington, D.C.: The World Bank. ${ }^{17}$ Organization for Economic Coordination and Development, Working Party on Aid Effectiveness, Task Team on Health as a Tracer Sector (2011) Progress and challenges in aid effectiveness. What can we learn from the health sector? Final report. Paris: OECD/WP EFF/TT-HATS.

${ }^{18}$ Lu, C., et al. (2010) Public financing of health in developing countries: a crossnational systematic analysis. The Lancet 375(9723): 1375-1387

${ }^{19}$ World Health Organization, World Bank, GAVI, and Global Fund (2010) Monitoring and evaluation of health system strengthening: an operational framework. Geneva: WHO. 
${ }^{20}$ Edward, A., Peters, D.H., Daniels, A., Rang, Y., and Matsubayashi, T. (2009) Review of Strategies to Strengthen the Performance of Health Organizations. In: D.H. Peters et al. (eds.) Improving Health Service Delivery in Developing Countries. From Evidence to Action. Washington, DC: The World Bank.

${ }^{21}$ Peters, D.H., El-Saharty, S., Siadat, B., Janovsky, K., and Vujicic, M. (eds.) (2009) Improving Health Service Delivery in Developing Countries. From Evidence to Action. Washington, DC: The World Bank.

${ }^{22}$ Pawson, R., Greenhalgh, T., Harvey, G., and Walshe, K. (2005) Realist review. A new method of systematic review designed for complex policy interventions. Journal of Health Services Research and Policy 10: 21-34.

${ }^{23}$ De Savigny, D., and Adam T. (Eds) (2009) Systems thinking for health systems strengthening. Geneva: Alliance for Health Policy and Systems Research and WHO.

${ }^{24}$ Victora, C.G., Black, R.E., Boerma, J.T., and Bryce, J. (2010) Measuring impact in the Millennium Development Goal era and beyond: a new approach to large-scale effectiveness evaluations. Lancet 377(9759): 85-95.

${ }^{25}$ Contandriopoulos, A.P., Champagne, F., Denis, J.L., and Avargues, M.C. (2000) Evaluation in the health sector: a conceptual framework. Revue d'Epidémiologie et de Santé Publique 48(6): 517-39.

${ }^{26}$ Ritchie, J., and Lewis, J. (2003) Qualitative Research Practice. A Guide for Social Students and Researchers (First Edition). London: Sage Publications.

27 Hasson, H. (2010) Systematic evaluation of implementation fidelity of complex interventions in health and social care. Implementation Science 5(67).

${ }^{28}$ Sundewall, J., Forsberg, B.C., Jönsson, K., Chansa, C., and Tomson, G. (2009) The Paris Declaration in practice: challenges of health-sector aid coordination at the district level in Zambia. Health Research Policy and Systems 7(14). 
${ }^{29}$ World Health Organization Maximizing Positive Synergies Collaborative Group (2009) An assessment of interactions between global health initiatives and country health systems. Lancet 373: 2137-69.

${ }^{30}$ Ooms, G., Hercot, D., Yibeltal, A., and Van Damme, W. (2010) The New Dichotomy in Health Systems Strengthening and the Role of Global Health Initiatives: What Can We Learn from Ethiopia? Journal of Public Health Policy 31(1): 102-109.

${ }^{31}$ World Health Organization (2008) Measuring Health Systems Strengthening and Trends: A Toolkit for Countries. Toolkit on monitoring health systems strengthening. Geneva: WHO.

${ }^{32}$ Van Olmen, J., Criel, B., Van Damme, W. et al. (2010) Analysing Health Systems to Make Them Stronger. Studies in Health Services Organisation and Policy 27.

${ }^{33}$ Paul, E., and Dujardin, B. (2006) The Health Sector-Wide Approach in Mali: Report of the second mission of the GRAP-SWAP to Mali, 6-16 March, http://www.grap-swap.be

${ }^{34}$ Dujardin, B., Laokri, S., Paul, E., and Samaké, S. (2007) Analysis of the Health SectorWide Approach (SWAp) dynamics in Mali. Tropical Medicine \& International Health 12(S1). ${ }^{35}$ Samaké, S. (eds.) (2009) L'approche sectorielle dans le domaine de la santé au Mali. Bamako, Mali : Coopération Technique Belge and Ministère de la Santé du Mali.

${ }^{36}$ Samaké, S., Berthé, I., Cissé, S.Y., and Paul, E. (2011) The results achieved through implementing the Paris Declaration in the health sector in Mali. Paper for the OECD/WP EFF/TT-HATS final report.

${ }^{37}$ Paul, E. (2011) Documenting results of efforts to improve health aid effectiveness: Mali case study, October, http://www.grap-pa.be

${ }^{38}$ Lawson, A. et al. (2011) Joint evaluation of budget support operations in Mali, 2003-2009. Eco-Consult and consorts for the European Commission of the European Union, Belgium, and Canada. Pilot exercise of the Development Assistance Committee/OECD. 
${ }^{39}$ Paul, E., \& Vandeninden, F. (2012) Foreign Aid Transaction Costs: What are they and how are they minimised? Development Policy Review, 30(3): 283-304.

${ }^{40}$ République du Mali, Ministère de la Santé, Cellule de Planification et de Statistique du secteur santé, développement social, promotion de la famille (2011) Evaluation du Plan de Développement Sanitaire et Social, Draft n 1 , May.

${ }^{41}$ World Health Organization (2012) Trends in maternal mortality 1990-2010. Geneva: WHO.

${ }^{42}$ UNICEF (2011) Levels \& Trends in Child Mortality Report, N

${ }^{43}$ République du Mali, CPS secteur santé, développement social et promotion de la famille, Institut national de la statistique (2010) Mali. Enquête par grappe à indicateurs multiples. 


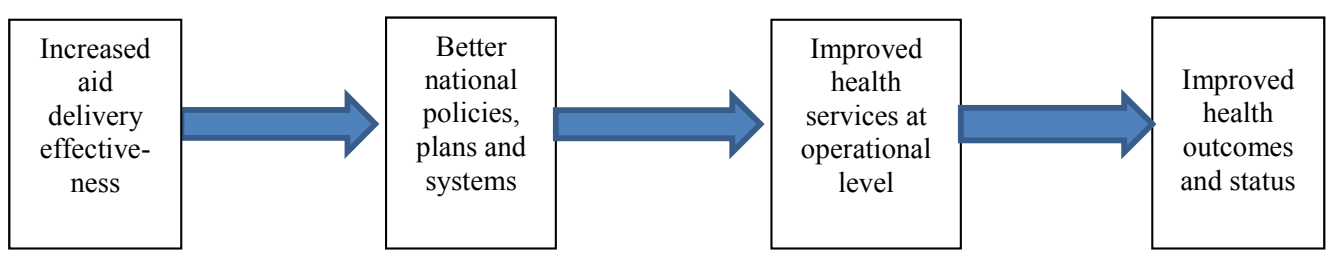

Figure 2 : Behavioral view of the rationale of the Paris Declaration and IHP+ in the health sector

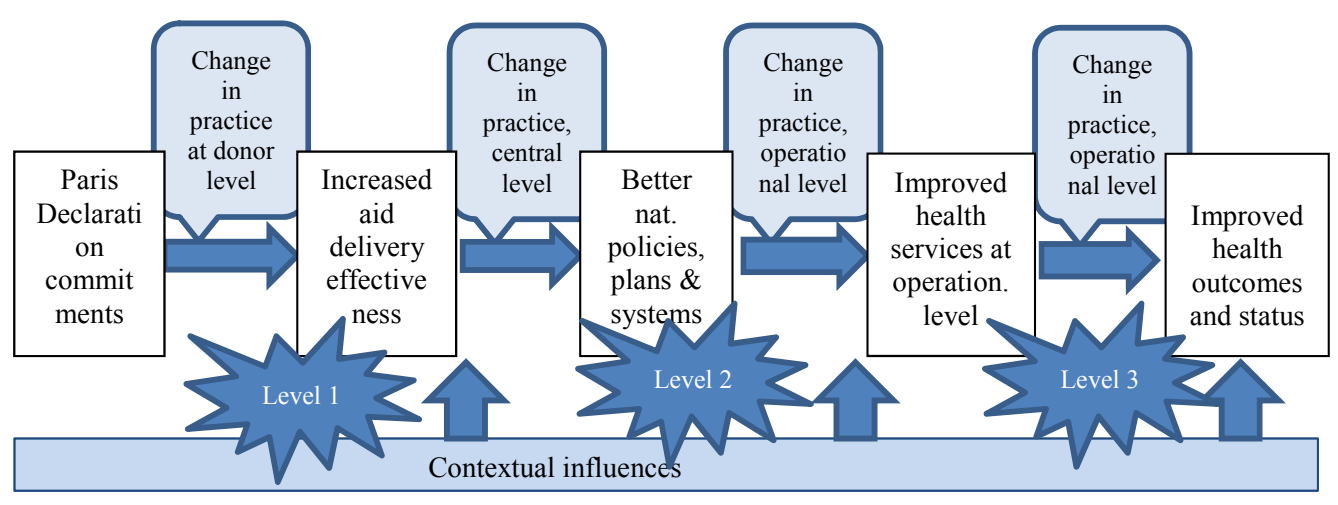

\footnotetext{
${ }^{i}$ Note that some global health initiatives have extrapolated the number of lives saved from their interventions; transposed to aid effectiveness and HSS, a similar practice would mean extrapolating that if for example an $80 \%$ reduction in mortality rates can be attributed to HSS, and $75 \%$ of HSS can be attributed to aid, then $60 \%$ of lives saved are attributable to aid; this, however, is not credible from a scientific point of view.

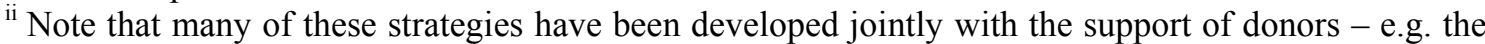
national child survival strategy resulted from a UNICEF project in various pilot regions, and has since been scaled-up; the expanded programme on immunisation is also the result of collaboration between the MoH, WHO, UNICEF, GAVI and other partners.
} 